\begin{tabular}{ccc}
\hline & International Journal of Engineering \& Technology, 7 (4.38) (2018) 1112-1114 \\
SPC & Website: $w$ w w.sciencepubco.com/index.php/IJET \\
Research paper & Technology \\
\hline
\end{tabular}

\title{
Mathematical Modeling of Helicopter Dynamics with an External Sling Load
}

\author{
Vadim Viktorovich Efimov $^{1 *}$, Konstantin Olegovich Chernigin ${ }^{1}$, Nikolay Ivanovich Nikolaykin ${ }^{1}$, \\ Vadim Vadimovich Vorob'ev ${ }^{1}$, Mikhail Semenovich Kublanov ${ }^{1}$ \\ ${ }^{1}$ Moscow State Technical University of Civil Aviation, Kronshtadtsky Boul., 20, Moscow, 125993, Russian Federation \\ *Corresponding author E-mail: vadim_v_efimov@bk.ru
}

\begin{abstract}
The article shows the urgency of the development of theoretical methods for studying the dynamics of the flight of a helicopter with an external sling load aimed at ensuring the flight operation safety when transporting loads. A mathematical model of the helicopter flight dynamics with an external sling load is described. The assumptions made are indicated. The load coordinate systems are introduced and described. The systems of equations of acting forces and moments are presented, which are derived considering the accelerated movement of the load's slinging point on the helicopter with its translational and rotational motion.
\end{abstract}

Keywords: flight dynamics, helicopter, load on an external sling, slung load system, numerical experiment, flight testing.

\section{Introduction}

The use of helicopters for the external sling (ES) load transportation and the conduct of various aerial works using the ES has a proved high practical efficiency. However, even today, the developers and operators of helicopters, like any other aircraft, have the task of steadily increasing the efficiency of their operation while ensuring the required level of flight safety (FS).

To ensure high efficiency and safety of air service and aviation operations, it is recommended that the range of permissible velocity for a helicopter with an external sling load be as wide as possible or at least be known in advance for the purpose of work planning. The limits of this range are largely determined by the ES load dynamics and its impact on the helicopter. With certain combinations of load parameters and flight parameters, the task of load transportation may prove unsafe or even impossible. In this regard, it is important to predict the dynamics of a load in order to determine the safe modes of its transportation on ES.

Many authors in Russia [1-3] and other countries [4-6] were engaged in the development of mathematical models (MM) of helicopter dynamics with external sling load. Theoretical methods include analytical calculations and computational experiments (CE) with the use of numerical simulation. To carry out analytical calculations and CE, it is necessary to develop MM and related software, which in turn will help to reduce the risks of air companies [7] when transporting loads and/or economic risks [8, 9].

However, until now the prediction of the load dynamics on the helicopter's ES has been carried out mainly on the basis of experimental research methods, usually by flight testing (FT). These research methods require significant financial investments and therefore may have low efficiency. In this regard, it is necessary to develop and improve theoretical methods for ensuring the safety of flight operations of helicopters when transporting loads on an external sling.

This work uses the MM, based on the provisions described earlier in works $[10,11]$.

\section{Materials and methods}

To solve the problems of ensuring the efficiency and safety of helicopter flights with the help of theoretical methods, the MM of interaction between the helicopter and external sling load was developed. The main assumptions used for the model generation are:

- a helicopter and load are considered absolutely rigid bodies;

- the aerodynamic characteristics of a helicopter and load are considered preset and unchanged;

- non-stationary aerodynamic effects are not taken into account;

- the mass-inertial characteristics of a helicopter and load (masses and moments of inertia) are considered preset and unchanged;

- the sling of a load is carried out with a single weightless wire attached at one point to the helicopter with the help of an ideal spherical joint.

To derive the equations and determine the parameters of the helicopter's motion, the earth-centered $\left(\mathrm{O}_{\mathrm{c}} \mathrm{X}_{\mathrm{c}} \mathrm{Y}_{\mathrm{c}} \mathrm{Z}_{\mathrm{c}}\right)$, body-fixed $(\mathrm{OXYZ})$, normal $\left(\mathrm{OX}_{\mathrm{g}} \mathrm{Y}_{\mathrm{g}} \mathrm{Z}_{\mathrm{g}}\right)$ and wind-fixed $\left(\mathrm{OX}_{\mathrm{a}} \mathrm{Y}_{\mathrm{a}} \mathrm{Z}_{\mathrm{a}}\right)$ coordinate systems, widely used in studying the flight dynamics of aircraft.

Moreover, to describe the mutual position of the helicopter and load, as well as the cargo itself relative to the earth-centered coordinate system, it is necessary to introduce a number of coordinate systems associated with the load and the wire on which it is slung.

On the helicopter, the wire is fixed at some point $\mathrm{O}_{1}$, which does not coincide with the center of mass of the helicopter at the sling point (Figure 1). Place in this point the coordinate origin of the system $\mathrm{O}_{1} \mathrm{X}_{\mathrm{g} 1} \mathrm{Y}_{\mathrm{g} 1} \mathrm{Z}_{\mathrm{g} 1}$. The axes of this coordinate system align the 
direction of the corresponding axes of the normal coordinate system of the helicopter $\mathrm{OX}_{\mathrm{g}} \mathrm{Y}_{\mathrm{g}} \mathrm{Z}_{\mathrm{g}}$. Thus, the coordinate system $\mathrm{O}_{1} \mathrm{X}_{\mathrm{g} 1} \mathrm{Y}_{\mathrm{g} 1} \mathrm{Z}_{\mathrm{g} 1}$ moves translationally relative to the earth-centered coordinate system and the normal coordinate system of the helicopter. Let us call $\mathrm{O}_{1} \mathrm{X}_{\mathrm{g} 1} \mathrm{Y}_{\mathrm{g} 1} \mathrm{Z}_{\mathrm{g} 1}$ the normal coordinate system of a sling point.

Introduce the body-fixed coordinate system of the wire $\mathrm{O}_{1} \mathrm{X}_{1} \mathrm{Y}_{1} \mathrm{Z}_{1}$. It also starts at the sling point (Figure 2). The axes of this coordinate system are rigidly connected to the wire like the axes of the body-fixed coordinate system of the helicopter OXYZ, while the axis $\mathrm{O}_{1} \mathrm{Y}_{1}$ is always aligned along the wire upward. Since, as was assumed above, the wire is fixed at the sling point with a spherical joint, the position of the wire (the position of the body-fixed coordinate system of the wire $\left.\mathrm{O}_{1} \mathrm{X}_{1} \mathrm{Y}_{1} \mathrm{Z}_{1}\right)$ relative to the normal earth coordinate system of the sling point $\mathrm{O}_{1} \mathrm{X}_{\mathrm{g} 1} \mathrm{Y}_{\mathrm{g} 1} \mathrm{Z}_{\mathrm{g} 1}$ can be described in the same way as in the description of the mutual position of the helicopter coordinate systems OXYZ and $\mathrm{OX}_{\mathrm{g}} \mathrm{Y}_{\mathrm{g}} \mathrm{Z}_{\mathrm{g}}$, i.e. with the help of yaw angle $\psi_{1}$, pitch angle $\vartheta_{1}$ and roll angle $\gamma_{1}$.

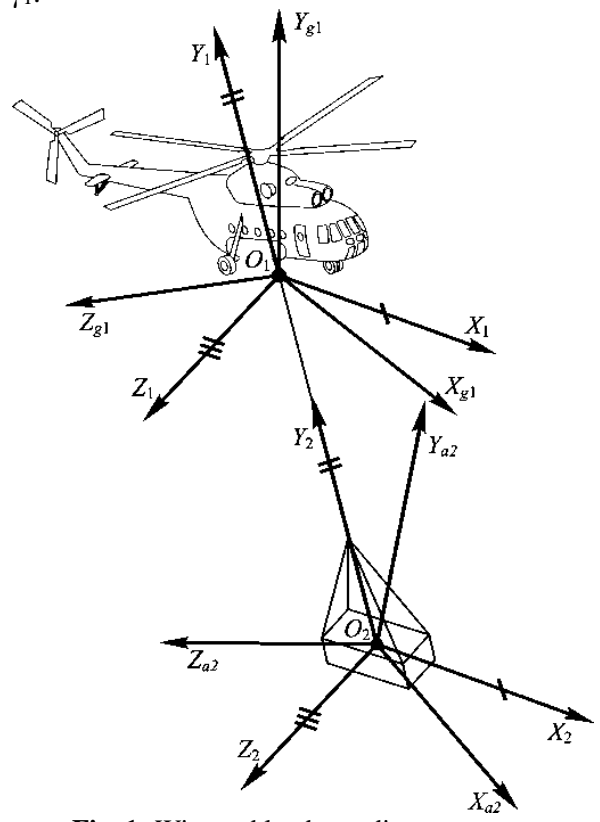

Fig. 1: Wire and load coordinate systems

The body-fixed coordinate system of a load has a beginning in the mass center of load (point $\mathrm{O}_{2}$ ) and is rigidly connected with it. At the first approximation, the coordinate system $\mathrm{O}_{2} \mathrm{X}_{2} \mathrm{Y}_{2} \mathrm{Z}_{2}$ will be considered rigidly connected not only with the load but also with the wire, i.e. its axes are always parallel to the axes of the bodyfixed coordinate system of the wire $\mathrm{O}_{1} \mathrm{X}_{1} \mathrm{Y}_{1} \mathrm{Z}_{1}$ and align along their direction.

The wind-fixed coordinate system of a load is inherently similar to the corresponding coordinate system of the helicopter. Whereas its beginning is in the mass center of the load $\mathrm{O}_{2}$ (Figure 2), the axis $\mathrm{O}_{2} \mathrm{X}_{\mathrm{a} 2}$ aligns the airspeed of the load and coincides with it in the direction, the axis $\mathrm{O}_{2} \mathrm{Y}_{2}$ is located in the plane in $\mathrm{O}_{2} \mathrm{X}_{2} \mathrm{Y}_{2}$ and is directed upward, the axis $\mathrm{O}_{2} \mathrm{Z}_{\mathrm{a}}$ forms the right-hand coordinate system with the axes $\mathrm{O}_{2} \mathrm{X}_{\mathrm{a} 2}$ and $\mathrm{O}_{2} \mathrm{Y}_{\mathrm{a} 2}$. The angular position of the given coordinate system with respect to the associated coordinate system of the load $\mathrm{O}_{2} \mathrm{X}_{2} \mathrm{Y}_{2} \mathrm{Z}_{2}$ is defined by the angles of attack $\alpha_{2}$, and gliding $\beta_{2}$, which are determined by the rules similar to those used to determine the angles of attack and gliding of the helicopter.

\section{Results and discussion}

Equations of motion of the helicopter as an absolutely rigid body in vector form are expressed as: $m \frac{d \vec{V}}{d t}=\vec{F}, \frac{d \vec{K}}{d t}=\vec{M}$

where $\mathrm{m}$ - mass of the helicopter; $\vec{V}$ - velocity vector of helicopter center mass relative to the earth-centered coordinate system; $\vec{F}-$ the resultant of all external forces acting on the helicopter; $\vec{K}-$ the kinetic moment relative to the mass center of the helicopter; $\vec{M}-$ the main moment of the external forces acting on the helicopter, relative to the mass center of the helicopter.

The left-hand sides of equations (1) are investigated in sufficient detail. Let us reveal their right parts. In vector form, the equation of forces acting on a helicopter is as follows:

$\vec{F}=\overrightarrow{R_{M R}}+\overrightarrow{T_{T R}}+\overrightarrow{R_{A}}+\vec{G}+\overrightarrow{R_{W}}$

where $\quad \overrightarrow{R_{M R}}-$ the resultant force of main rotor (MR); $\overrightarrow{T_{T R}}-$ tail rotor (TR) thrust; $\overrightarrow{R_{A}}-$ the resultant of the aerodynamic forces acting on the helicopter's glider; $\vec{G}-$ gravity force; $\overrightarrow{R_{W}}-$ tension force of the wire.

In turn, the main moment of the external forces acting on the helicopter is presented in the following vector sum:

$\vec{M}=\overrightarrow{M_{M R}}+\overrightarrow{M_{T R}}+\overrightarrow{M_{A}}+\overrightarrow{M_{W}}$

where $\quad \overrightarrow{M_{M R}}-$ the moment created by MR; $\overrightarrow{M_{T R}}-$ the moment created by TR; $\overrightarrow{M_{A}}-$ the aerodynamic moment of the airframe of the helicopter; $\overrightarrow{M_{W}}-$ the moment from the tension of the wire. In this work, only the forces and moments that arise when the wire is tensioned are considered.

The tension force of the wire $\overrightarrow{R_{W}}$ on which the load is slung depends on the gravity force of the load, the aerodynamic force acting on the load, and also on the inertial forces that arise when the load is swinging relative to the slung point and because of the accelerated displacement of the hanging point itself. Thus, in order to determine the value of the tension force of the wire, it is necessary to find the projection of the resultant of all forces acting on the load $\overrightarrow{R_{l d}}$ on a direction that coincides with the direction of the wire.

The resultant $\overrightarrow{R_{l d}}$ is represented in the following vector sum:

$\overrightarrow{R_{l d}}=\overrightarrow{G_{l d}}+\overrightarrow{R_{A . l d}}+\overrightarrow{J_{c f}}+\overrightarrow{J_{s p}}$

where $\quad \overrightarrow{G_{l d}}-$ the gravity force of the load; $\overrightarrow{R_{A . l d}}-$ aerodynamic force acting on the load; $\overrightarrow{J_{c f}}-$ the centrifugal force of inertia arising in the process of accelerated motion of the load; $\overrightarrow{J_{s p}}-$ the inertia force that arises from the accelerated motion of the slung point.

Find the projection of the force $\overrightarrow{R_{l d}}$ on the axis of the body-fixed coordinate system of the wire:

$\left\{\begin{array}{c}R_{l d . x 1}=G_{l d . x 1}+X_{l d}+J_{s p . x 1} \\ R_{l d . y 1}=G_{l d . y 1}+Y_{l d}+J_{c f . y 1}+J_{s p . y 1} \\ R_{l d . z 1}=G_{l d . z 1}+Z_{l d}+J_{s p . z 1}\end{array}\right.$

The force $R_{l d . y 1}$ acts along the axis $\mathrm{O}_{1} \mathrm{Y}_{1}$ of the body-fixed coordinate system of the wire, i.e. along the wire, therefore, it is the desired tension force the wire:

$R_{w}=R_{l d . y 1}$

In order to find its direction, it is necessary to integrate the equations of cargo movement and find the angles of the roll $\gamma_{1}$, pitch $\vartheta_{1}$ and yaw $\psi_{1}$ of the "wire -load" system. Then, it is easy to determine the projections of this force on the axis of the normal coordinate system of the slung point: 


$$
\left\{\begin{array}{c}
R_{w . x g 1}=R_{w}\left(\sin \psi_{1} \cdot \sin \gamma_{1}-\cos \psi_{1} \cdot \sin \vartheta_{1} \cdot \cos \gamma_{1}\right. \\
R_{w \cdot y g 1}=R_{w} \cos \vartheta_{1} \cdot \cos \gamma_{1} \\
R_{w . z g 1}=R_{w}\left(\cos \psi_{1} \cdot \sin \gamma_{1}+\sin \psi_{1} \cdot \sin \vartheta_{1} \cdot \cos \gamma_{1}\right.
\end{array}\right.
$$

Find the projections of the vector $\overrightarrow{R_{W}}$ on the axis of the body-fixed coordinate system of the helicopter: $R_{w . x}, R_{w . y}, R_{w . z}$ Then find the components of the moment $\overrightarrow{M_{W}}$ arising from the action of the force $\overrightarrow{R_{W}}$ with respect to the center mass of the helicopter, along with the axes of the same coordinate system:

$$
\left\{\begin{array}{c}
M_{w \cdot x}=R_{w . y} Z_{w}+R_{w \cdot z}\left(r_{s p . y b}-y_{w}\right) \\
M_{w \cdot y}=-R_{w \cdot x} Z_{w}-R_{w \cdot z}\left(r_{s p \cdot x b}-x_{w}\right) \\
M_{w \cdot z}=-R_{w \cdot x}\left(r_{s p . y b}-y_{w}\right)+R_{w \cdot y}\left(r_{s p \cdot x b}-x_{w}\right)
\end{array}\right.
$$

Thus, the problem of describing the interaction of a helicopter and load on an external sling can be solved.

Based on the above-described MM, the HeliCargo software package was developed, which allows carrying out a CE with a virtual Mi-8MTV helicopter transporting load on ES. With the help of this software complex, the adequacy of the MM was checked. This check was carried out both for the equilibrium conditions of the load and for the conditions for its oscillatory motion.

To verify the adequacy of the MM under equilibrium condition, flight test data were used with an empty helibucket for fire extinguishing (VSU-15). Figure 2 presents the results of the conducted CE and FT, which show that, from both the qualitative and quantitative points of view, the MM cargo adequately reproduces the change in the angle of pitch of the wire $\vartheta_{1}$, depending on the horizontal flight speed of the helicopter $\mathrm{V}_{\mathrm{hf}}$

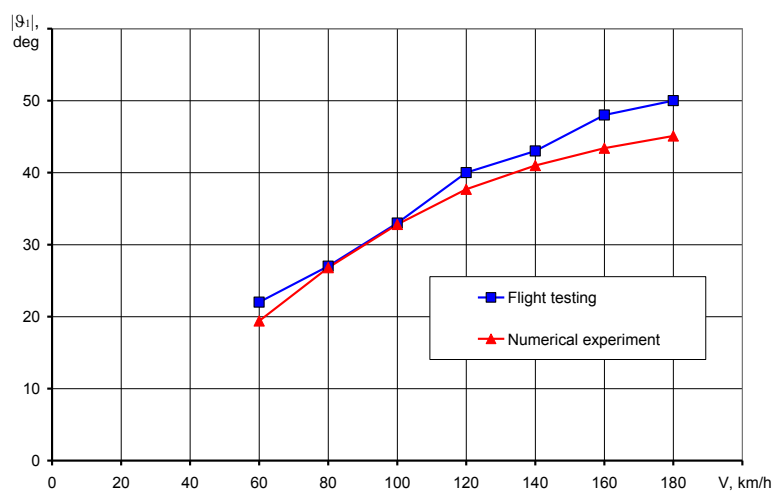

Fig. 2: Dependence of the wire pitch angle change from the speed of steady flight

To verify the adequacy of the MM in the modeling of the load oscillations, the results of the CE were compared with the results of the experiment with the load model in the wind tunnel [12].

The carried out experiments have shown that for certain geometric, aerodynamic, mass-inertial characteristics of the cargo and the length of the wire in a certain range of wind velocity, the self-oscillation of the cargo may occur, which corresponds to the conducted CE [13].

\section{Conclusion}

The above-described dynamics' MM of the "ES cargo - helicopter" system and the software developed on its basis have sufficient adequacy for solving the problems of ensuring integrated transport safety, including the safety of helicopter flights during the transportation of cargo with the external sling and, in particular, to eliminate the ecological and economic danger of aviation accidents $[8,14]$.
The HeliCargo software allows analyzing the safety of transportation of any cargo with given aerodynamic, geometric and mass-inertial parameters on the external sling of the helicopter, analyzing the special situations arising during the transportation of cargo to the helicopter's external sling, investigating accidents with helicopters transporting cargo on ES, to reduce the number of flight experiments with cargoes on ES, evaluating the efficiency of cargo stabilization tools.

Further, it is planned to reveal qualitatively new dependencies of the flight dynamics of such a complex system and enable the determination of safe modes of cargo transportation with the helicopter's external sling.

\section{References}

[1] V.B. Kozlovskiy, M.S. Kublanov, Matematicheskaya model' poleta vertoleta $\mathrm{s}$ gruzom na vneshney podveske [Mathematical model of flight of a helicopter with a load on an external sling], Nauchnyy vestnik MGTU GA 72 (2004) 5-9.

[2] E.A. Kuklev, S.S. Pavlov, Otsenka vozmozhnosti zabrosa trosa s pustoy emkost'yu na bol'shie ugly pri ee transportirovke vertoletom [Assessment of the possibility of casting a wire with an empty container at large angles when it is transported by a helicopter], Nauchnyy vestnik MGTU GA 119 (2007) 128-133.

[3] A.N. Sviridenko, Matematicheskaya model' sistemy "vertolet gruz na vneshney podveske" [Mathematical model of the system "helicopter - cargo on external sling"], Nauchnyy vestnik MGTU GA 111 (2007) 129-134.

[4] L.S. Cicolani, G. Kanning, Equations of Motion of Slung-Load Systems, Including Multilift Systems, NASA (1992), NASA-TP3280 .

[5] R.A. Stuckey, Mathematical Modelling of Helicopter Slung-Load Systems, Air Operations Division Aeronautical and Maritime Research Laboratory (2002), DSTO-TR1257.

[6] M. Bisgaard, J.D. Bendtsen, A. La Cour-Harbo, Modelling of Generic Slung Load System, AIAA Modeling and Simulation Technologies Conference and Exhibit 21-24 August 2006, Keystone, CO (2006).

[7] A.V. Aleksandrova, E.V. Protsenko, V.D. Sekerin, et al., Risk Management Tools in Russian Aviation Engineering Companies, Journal of Applied Economic Sciences XI (1(39)) (2016) 18-23.

[8] V.D. Sekerin, V.V. Burlakov, O.A. Dzyurdzya, et al., Peculiarities of Forecasting Competitiveness of Innovations for Industrial Enterprises, International Journal of Economics and Financial Issues 5 (2015) 54-60.

[9] M.N. Dudin, E.E. Frolova, N.A. Lubenets, et al., Methodology of analysis and assessment of risks of the operation and development of industrial enterprises, Quality: Access to Success 17(153) (2016) 53-59.

[10] V.V. Efimov, Matematicheskoe opisanie dvizheniya gruza na vneshney podveske vertoleta [Mathematical description of the movement of cargo on the external sling of the helicopter], Nauchnyy vestnik MGTU GA 111 (2007) 121-128.

[11] V.B. Kozlovskiy, S.A. Parshentsev, V.V. Efimov, Vertolet gruzom na vneshney podveske [Helicopter with cargo on external sling], Mashinostroenie/Mashinostroenie-Polet, Moscow 2008.

[12] V.V. Efimov, K.O. Chernigin, Yu.A. Bykov, Otsenka adekvatnosti matematicheskoy modeli dinamiki gruza na vneshney podveske vertoleta [Evaluation of the adequacy of the mathematical model of cargo dynamics on the external sling of a helicopter], Nauchnyy vestnik MGTU GA 172 (2011) 67-71.

[13] V.V. Efimov, Avtokolebaniya gruzov na trosovoy vneshney podveske vertoleta [Self-oscillation of loads on the wire external sling of the helicopter], Obshcherossiyskiy nauchno-tekhnicheskiy zhurnal "Polet" 12 (2011) 23-28.

[14] N.I. Nikolaykin, N.E. Nikolaykina, V.D. Sekerin, et al. Environmental and Economic Model of an Aircraft Accident Evaluation, Journal of Environmental Management and Tourism VIII (5(21)) (2017) 1128-1135 